\author{
VÍCTOR RUIZ
}

\title{
Disposiciones para la construcción de una iglesia
}

La eterna sabiduría, que tocando de fin a fin fuertemente todas las cosas, las dispone con suave providencia [...]

Fray Isidro Félix de Espinosa ${ }^{\mathrm{I}}$

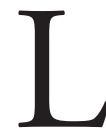
A ENORME EMPRESA que buscaba sedentarizar a los nativos pobladores del Norte fue encabezada por dos grandes instituciones franciscanas: los Colegios de Propaganda Fide de la Santa Cruz de Querétaro y el Colegio de Nuestra Señora de Guadalupe de Zacatecas. Desde su fundación, en I683 y I 707, respectivamente, la intención de estos colegios fue preparar y sostener a misioneros para evangelizar y asentar en poblados a los indios que vivían en los extensos territorios de lo que actualmente son los estados de Tamaulipas, Nuevo León, Coahuila, Chihuahua, Sonora y Sinaloa, así como las Californias, Nuevo México, Arizona y Texas. Se trataba de establecer una disciplina religiosa, moral, social e industrial que permitiera incorporar a los indígenas a la forma de vida occidental. Para ello, los frailes idearon un lugar llamado genéricamente "misión", donde "las mujeres aprendieran a cocinar, coser, hilar y tejer y los hombres

I. Fray Isidro Félix de Espinosa, "Prefacio", Crónica de los Colegios de Propaganda Fide de la Nueva España (1746), Lino Gómez Canedo (ed.), Washington, D. C., Academy of American Franciscan History, 1964. 
a desmontar, construir, forjar, curtir, hacer canales, cuidar al ganado, trasquilar ovejas, además de entrenarse en la elaboración de artes y artesanías". ${ }^{2}$

En general, puede afirmarse que la mayoría de las misiones fundadas por los frailes franciscanos se transformaron con el paso del tiempo en poblados y ciudades. La idea de la misión como núcleo central que sirviera para el posterior desarrollo urbano se logró en muchos de los casos. Hoy los testigos más visibles de estas hazañas son las iglesias, que nacieron para informar sobre la ubicación del sitio misional y para darle forma.

Una muestra de lo anterior son las descripciones del fraile franciscano Juan Agustín de Morfi en su Viaje de Indios y Diario de Nuevo México. ${ }^{3}$ Veamos lo que dice de las misiones de Coahuila y Texas, las cuales estaban en pleno uso y funcionamiento cuando Morfi hizo su recorrido. El 2I de diciembre de 1777 llega por primera vez a las misiones coahuilenses. Comienza la descripción de la iglesia de misión de San Juan Bautista con el señalamiento de que "era grande, de crucero y con razonable arquitectura". Después aclara que en el obraje "se fabricaban frazadas y que la troje era competente". De San Bernardo, Morfi dice que se erigió "con el mismo pie, con igual método" que la de San Juan Bautista. La troje y el obraje los encontró "bien construidos y espaciosos". Concluye que esta misión era "la más rica por tener más número de indios, más fértil el terreno y más extensión de pastos".

Respecto a las misiones del Río San Antonio, dice que se encontraban situadas en la orilla de un hermoso río en la corta extensión de tres leguas. Vio la iglesia de San Antonio en construcción y presentaba "buen estado, sencilla y buena planta". Enseguida repite que todas las misiones estaban construidas con el "mismo gusto, como gobernadas por un propio método". Continúa con la misión de la Concepción, que estaba "situada en un bello terreno y con las mismas proporciones" que las demás. Su iglesia, señala, se había construido "de bóveda con una piedra tosca arenisca". Morfi queda admirado de la misión de San José y San Miguel de Aguayo, que "es verdaderamente la mejor de esta América, que puede llamarse corte de las demás". Menciona que tenía una "plaza de doscientas dieciséis varas en cuadro, con cuatro puertas iguales en los cuatro lienzos", y expresa que "nadie creería que en aquel desierto hubiese

2. Herbert Eugene Bolton, La misión como institución de frontera en el septentrión de la Nueva España, citado por David Weber, en El México perdido, ensayos sobre el antiguo norte de México I 540-I82I, México, Secretaría de Educación Pública (Sep Setentas, 265), I976, p. 50.

3. Fray Juan Agustín de Morfi, Viaje de Indios y Diario de Nuevo México (1779), México, Antigua Librería Robledo de José Porrúa e Hijos, I935. 
artificios tan delicados". De la misión de San Juan Capistrano sólo refiere que puede compararse con la misión de la Concepción; de San Francisco de la Espada, que "la vivienda de los padres no tenía arte ni pulidez, pero era bastante cómoda".

Como balance, el primer señalamiento importante es que Morfi hace mención de lo similar en los "pies" de construcción y el "método" usado en las misiones de Coahuila. Lo mismo sucede para San Antonio, donde todas las misiones, según su relato, estaban construidas sobre el "mismo gusto" y gobernadas por un "propio método". En efecto, las iglesias misionales tanto de Querétaro como de Guadalupe son dimensional y formalmente similares, a la vez que su organización comunitaria también presentaría gran similitud. Con atención a los aspectos formales, hay que preguntarnos: ¡ंes posible que nos encontremos ante un mismo modelo o, dicho con más precisión, una normativa a seguir aplicada a cada misión en función de un diseño considerado con antelación?

Para contestar a esta pregunta conviene considerar algunos aspectos de la relación entre los franciscanos y su arquitectura, empezando por la cuestión de los frailes constructores. Al indagar en los planes de estudio de los Colegios de Propaganda Fide, descubrimos que los frailes se preparaban en un periodo que variaba de uno a dos años, sin embargo, encontramos que la arquitectura no era considerada parte de la instrucción. ${ }^{4}$ No obstante, en el llamado "Método para misiones de infieles"' hallamos referencias a la importancia de los trabajos de edificación relacionados con el ámbito sagrado y al papel de los frailes en promoverlos. En primer lugar se cita la disposición real según la cual los frailes tienen que apoyar a los indios que trabajan en la construcción: "las iglesias de los indios incorporados en nuestra Corona, mandará hacer con ellos el mismo Capitán que los tiene a su cargo, y los padres sustentarán a los indios que trabajaren en dichas iglesias, y ellos por su propio bien lo harán sin paga de jornales". ${ }^{6}$ También se ordena que los indios asistan a la iglesia: "con la reverencia debida a tal lugar; dándoles a entender que aquélla es la casa de Dios, en la que conseguirán bienes espirituales y temporales si claman al Señor

4. El personal de Querétaro era fundamentalmente peninsular. El caso de Guadalupe Zacatecas es diferente, pues su personal era mayoritariamente criollo y novohispano. David Brading, Una iglesia asediada, el obispado de Michoacán I749-I8Io, México, Fondo de Cultura Económica, I994, p. 5 I.

5. Félix Saíz Diez, Los Colegios de Propaganda Fide en Hispanoamérica, Madrid, Raycar Impresores, 1969, p. I55.

6. Ibidem, p. 158 . 
y se convierten de todo corazón a abrazar con la práctica, la ley santa de Dios Nuestro Señor [...]". ${ }^{7}$ A partir de estas recomendaciones, es evidente que los frailes no estaban al margen de esta actividad.

Se confirma esta apreciación al constatar que hubo un ejemplar del tratado de Arte y uso de arquitectura de fray Lorenzo de San Nicolás, ${ }^{8}$ publicado en I729, en el acervo del convento de San Francisco de México. Los frailes franciscanos del siglo XVIII no estaban, por lo tanto, totalmente desprovistos de interés por la arquitectura. Sin embargo, una confirmación todavía más significativa la tenemos en un documento que encontramos entre los papeles del Colegio de la Santa Cruz de Querétaro, actualmente resguardados en el Archivo Histórico Franciscano de la Provincia de Michoacán, con sede en el convento franciscano de la ciudad de Celaya, en la parte destinada a la miscelánea del Fondo de las Misiones. El texto lleva por título Disposiciones para la construcción de una iglesia. ${ }^{9}$ Por la manufactura del papel y la marca de agua, podemos inferir que se trata de un documento de la primera mitad del siglo XVIII, y el color de la tinta y el carácter de los trazos corroboran este origen. Los rasgos de su caligrafía, así como el léxico utilizado, difieren poco de los documentos que lo acompañan. Es difícil precisar quién lo escribió, aunque por comparación con otros documentos del colegio es poco probable que haya sido un amanuense, ya que los trazos resaltan por su carácter individual. Seguramente el autor del texto fue un franciscano, ya que menciona "nuestro estado" de religiosos. Podría tratarse, por lo tanto, de un escrito realizado o copiado por algún misionero o visitador.

Es un texto breve, de una página, escrita por ambos lados, en donde el autor anotó de manera muy didáctica los pasos mínimos para entender una fábrica arquitectónica. El escrito contiene de manera clara y sin ambages las indicaciones básicas para el manejo de proporciones, el vaciado de las cimentaciones, la conformación de la planta, la construcción de paredes, el trazo y andamiaje de los arcos, la conformación de la puerta, y hace una consideración sobre los órdenes arquitectónicos. Veamos muy brevemente estas indicaciones.

\section{Ibidem, p. I64.}

8. Fray Lorenzo de San Nicolás, Arte y uso de arquitectura. Con el libro primero de Euclides, traducido en castellano. Primera parte. Compendiado por Fray Lorenzo de San Nicolás, agustino descalzo, arquitecto y maestro de obras, Plácido Baro López (ed.), Madrid, Biblioteca Nacional de Antropología e Historia, I729, clave I5, núm. II, p. I.

9. Anónimo, Disposiciones para la construcción de una iglesia, Archivo Histórico de la Provincia Franciscana de Michoacán (AHPFM), Ramo Misiones, letra K, leg. 27, núm. 26. Véase Anexo. 
DISPOSICIONES PARA LA CONSTRUCCIÓN

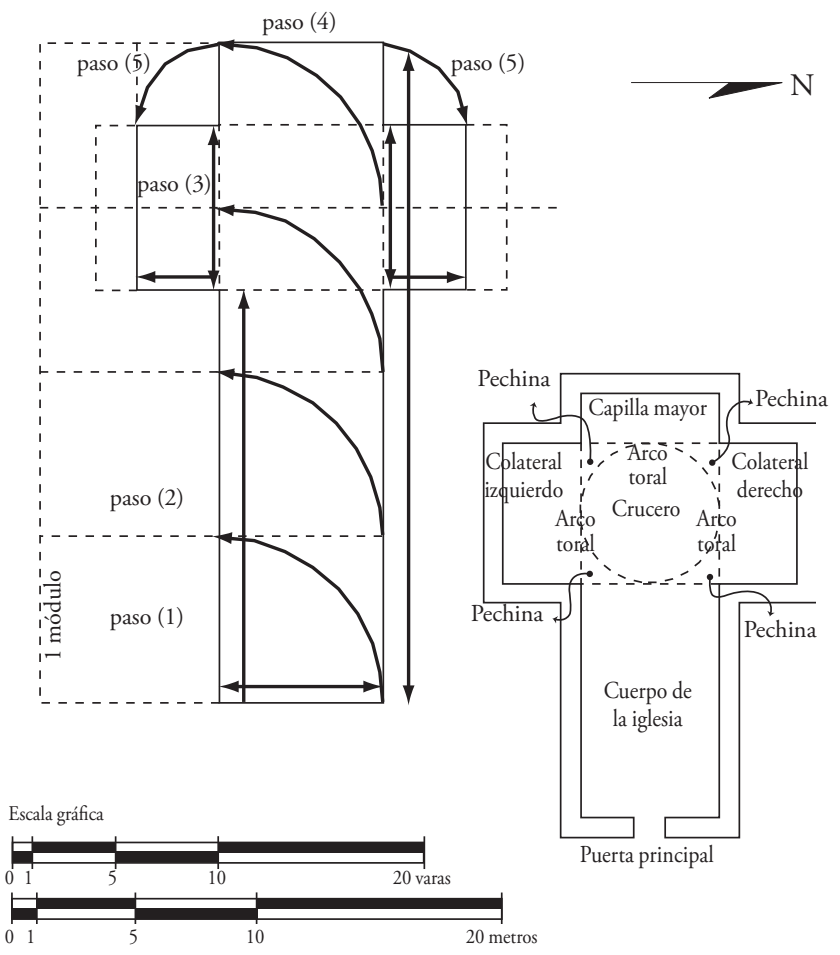

I. Restitución gráfica, arquitecta Patricia Maltos Pacheco, diciembre 2003.

Después de una exposición sobre proporciones y cimentaciones, se explica la manera de llevar a cabo el trazo de la planta. Para ello, el autor alude a tres cuestiones básicas: la forma, la proporción y la orientación, pero las mezcla en una sola indicación que dice:

Desde el lado de el poniente [...] se miden por la parte interior, corriendo las medidas para el oriente 20 varas, que siendo [...] el ancho de 8 corresponden las 20 dichas que son dos anchos y medio. Otro ancho, que es 8 varas se da al hueco que corre formando los brazos del crucero [...] A la capilla mayor se le da de fondo [...] 2 varas que con las dos que aquí se añaden [...] ajustan [...] 32 de largo. A cada brazo del crucero [...] se le dan de fondo [...] cuatro varas, y si fuesen seis, mejor; máxime si llevare colaterales.

Como puede observarse (fig. I), la manera de formar la planta en términos prácticos es bastante sencilla. Si tomamos como base la orientación y la pro- 

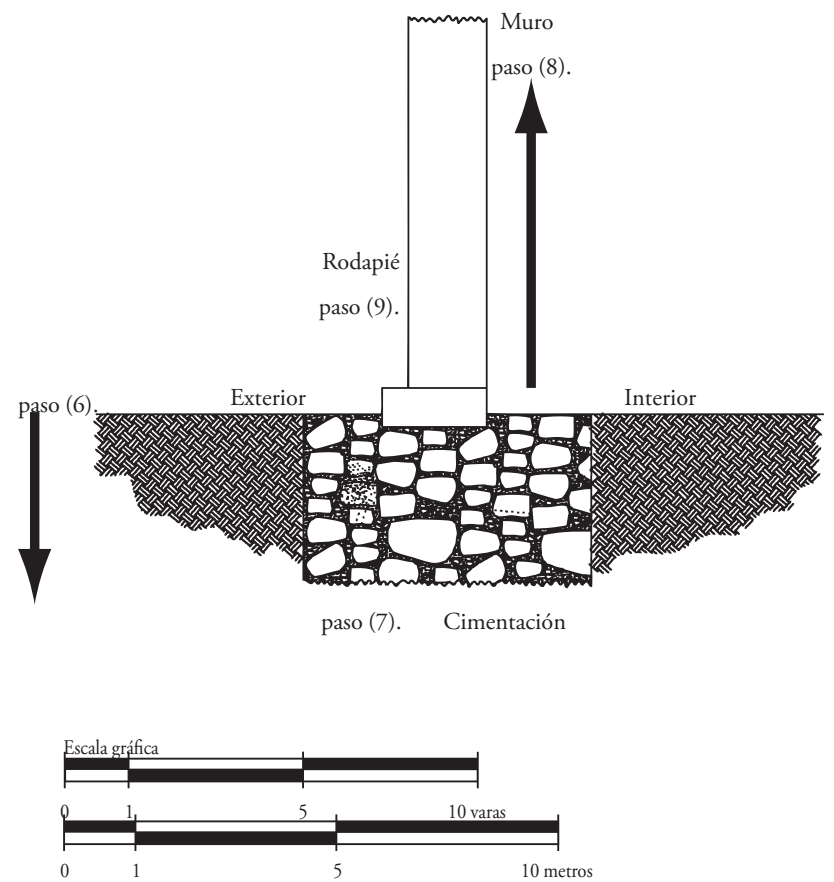

2. Restitución gráfica, arquitecta Patricia Maltos Pacheco, diciembre 2003.

porción, es posible diseñar una planta de una nave con crucero, de ocho varas de ancho por 32 varas de largo, con brazos de seis varas. Estas medidas básicas coinciden con las iglesias del Río Grande, San Antonio, Río Neches, San Gabriel y San Sabá, e incluso con algunas iglesias franciscanas de las Pimerías. De estas medidas resultaría un espacio interno de 300 varas cuadradas, útil para dar cabida aproximadamente a 250 usuarios. Es interesante que, de acuerdo con el visitador fray Antonio de Sevillano, las misiones del Río San Antonio presentaran un promedio de 300 pobladores. Las misiones del Río Grande sumaban 420 en San Bernardo, 344 en San Juan Bautista, 242 en San Francisco Solano y 302 en Nuestra Seńora de los Dolores. ${ }^{\text {IO }}$

La ejecución de la fábrica también está explicada a partir de tres elementos: cimentaciones, muros y arcos. Para las cimentaciones indica que:

Io. Antonio Sevillano de Paredes, Visita a las misiones del Río Grande del Norte, Archivo General de la Nación (AGN), Ramo Provincias Internas, ff. 3I a I9I. 


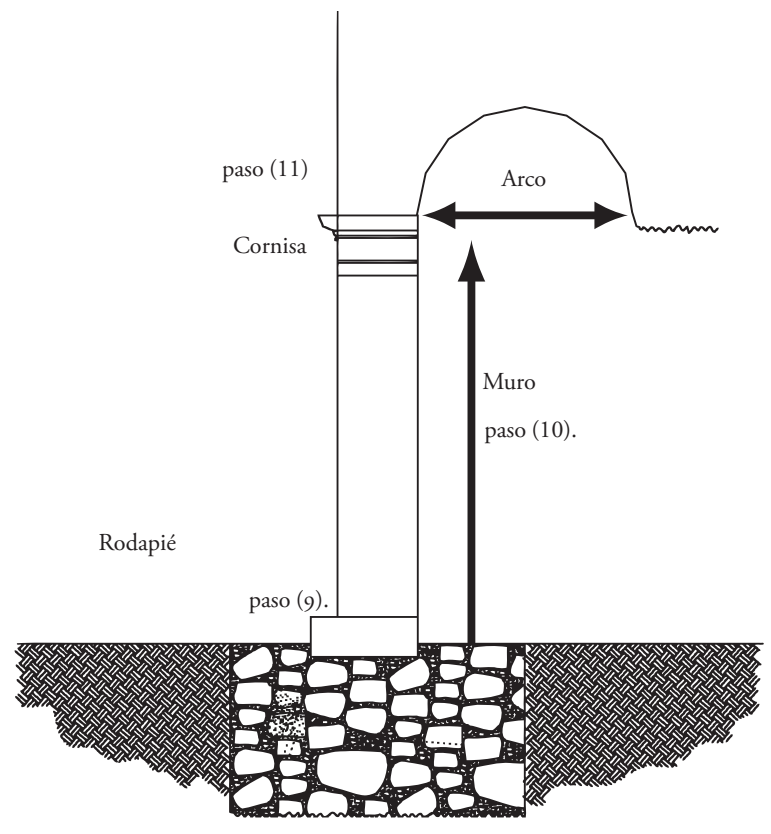

Cimentación

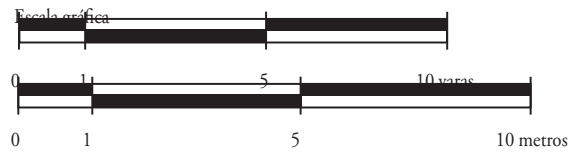

3. Restitución gráfica, arquitecta Patricia Maltos Pacheco, diciembre 2003 .

$[\ldots]$ se ha de cavar a plomo $[\ldots]$ hasta dos varas de profundo [...] se ha de abrir de 2 varas de ancho hasta enrasarlo a nivel [...] con media vara que lleve el rodapié fuera de la tierra [...] sobra para el resguardo de las aguas y de la obra [...] (fig. 2).

Respecto a los muros, dice que

$[\ldots]$ sobre el enrras del rodapiés se mide el grueso de la pared, que ha de tener [...] vara y media [...] va subiendo la pared hasta 8 varas que se ajustaran con la cornisa [...] desde esta altura [...] nacen los arcos, y bóvedas, pechinas, lunetas etc. (fig. 3). 
192

VÍCTOR RUIZ

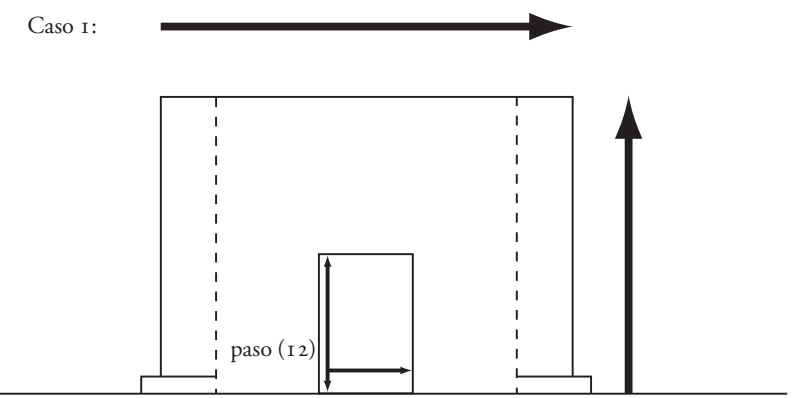

$$
\text { Caso 2: }
$$
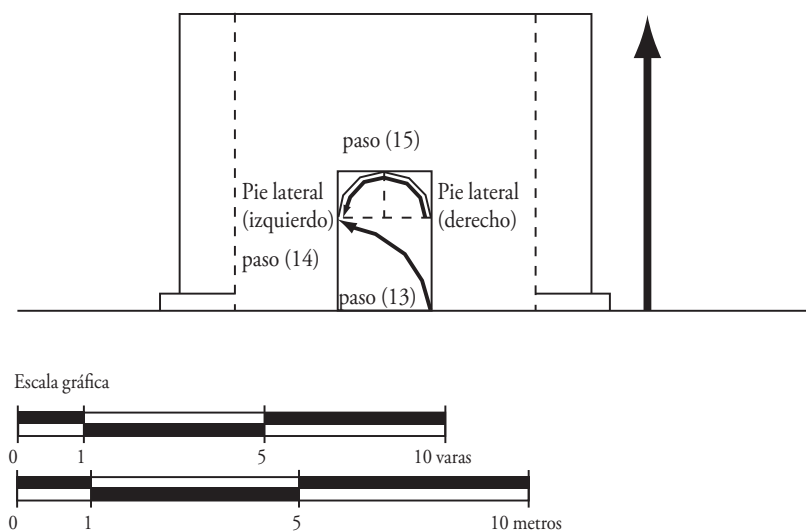

4. Restitución gráfica, arquitecta Patricia Maltos Pacheco, diciembre 2003.

Respecto a lo decorativo, indica que

[...] la puerta principal de la iglesia estará bien proporcionada si llevare dos varas y media de ancho y tres y tres cuartas de alto. Si fuere de medio punto, se le dará a los pies derechos, desde el alto del sardinel hasta el alto del capitel, dos varas y media y de aquí sale el medio punto, o semicírculo con vara y cuarta de diámetro desde el centro que ha de estar nivelado con los dos capiteles, línea recta. (fig. 4).

Estas indicaciones corresponden a la transportación de las proporciones desde la planta hacia los alzados, esto es, ajustar el ancho y el largo con la altura del edificio. El módulo básico a considerar es la puerta principal. Al tratar los ór- 


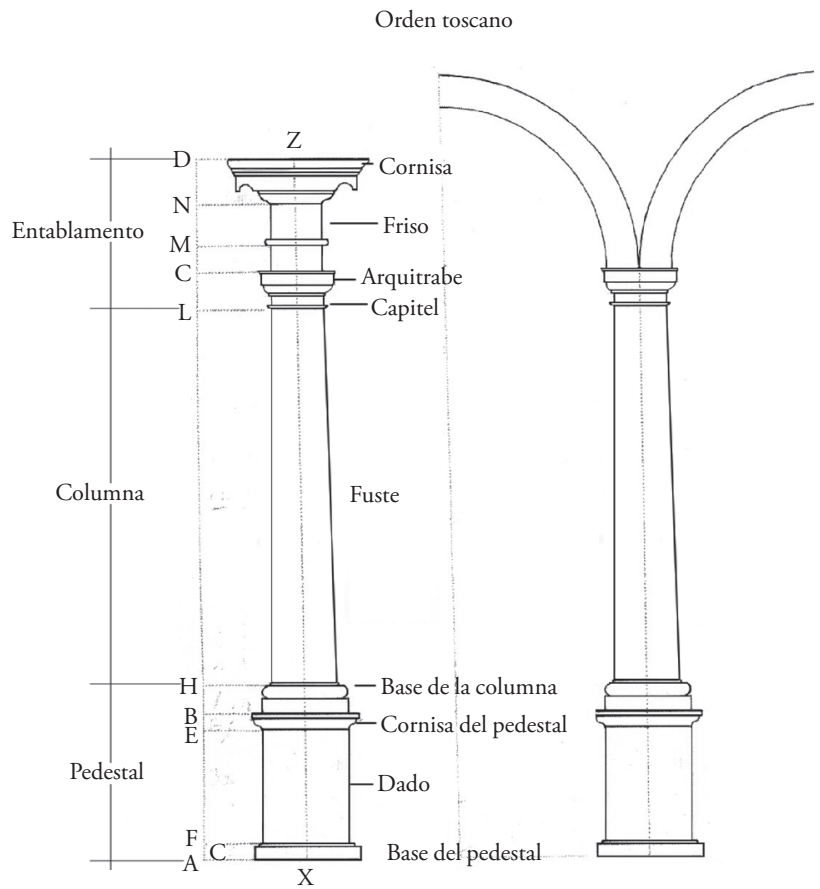

5. Restitución gráfica, arquitecta Patricia Maltos Pacheco, diciembre 2003.

denes menciona que: "según nuestro estado, y por más firme, y honesto será el toscano: y éste le dará luz, y gobierno para seguir la portada, o fachada y consiguientemente para toda la fabrica." (fig. 5). Esta indicación corrobora que el ideal de pobreza era considerado parte primordial de la imagen que los frailes de San Francisco querían presentar. Además, encontramos una notable coincidencia con fray Andrés de San Miguel:

dice bien este edificio [toscano] con las Órdenes Descalzas por su pobreza, que es bien digan las moradas con sus moradores, y así, como ellos en su vida monástica y estrechez demuestran pobreza y humildad, vestida de fortaleza, así también esta orden toscana demuestra pobreza por no estar tan adornada de molduras como las demás; demuestra humildad porque guarda la más baja proporción de todas; demuestra fortaleza por ser la más firme de todas. ${ }^{\text {II }}$

I I. Eduardo Báez Macías, Obras de fray Andrés de San Miguel, México, Universidad Nacional Autónoma de México-Instituto de Investigaciones Estéticas, I969, p. 84. 
En resumen, es muy probable que el documento aquí anexado haya sido utilizado como guía en la construcción de algunos templos de los frailes de Propaganda Fide, ya que conjunta no sólo los conocimientos necesarios para la edificación, sino que a la vez es sencillo y fácil de aplicar. Proporciona los elementos mínimos y necesarios en cuanto a forma y composición para la erección de una iglesia misional y también toma en cuenta la dimensión simbólica de las construcciones franciscanas.

Disposiciones para la construcción de una iglesia AHFPM, Ramo Misiones, letra K, leg. 27 , núm. 26. ${ }^{12}$

La Iglesia que se ha de hazer, si fuere bóveda, saldrá proporcionada con 8 varas de ancho, a que corresponden quatro anchos de largo, que son quatro veces 8 . ajustan 32; y dándole dos varas más al fondo del presviterio, para mas desahogo, tendrá de largo 32.

El cimiento se ha de abrir con 2.varas de ancho hasta enrrasarlo a nivel en el enrras, o superficie de la tierra: se ha de cavar a plomo quanto mejor se pueda hasta dos varas de profundo o mas, sino se halla tierra virgen; si antes se da en piedra, limpiar bien el cimiento que quede plano y mazizarlo con lechada y hormigón. Con media vara que lleve el rodapiés fuera de la tierra en la parte que estuviere mas alta, sobra para el resguardo de las aguas y de la obra; pero desde aquí se va tendiendo el nivel portada la circunferencia del rodapiés hasta acabar en donde se empezó.

Hase de abrir en forma de cruz perfecta; y para que assi salga se ha de repartir en esta forma; Desde el lado de el poniente (que aquí ha de tener la portada) se miden por la parte interior, corriendo las medidas para el oriente 20.varas, que siendo, como es, el ancho de 8 . corresponden las 20 dichas que son dos anchos y medio: Otro ancho, que es 8 varas se da al hueco que corre formando los brazos del crucero, de arco toral, a arco toral de la Capilla maior, este va sin cimiento. A la Capilla maior se le da de fondo otro medio ancho que son 2 varas que con las dos que aquí se añaden (como antes queda advertido,) ajustan las dichas 32 de largo. A cada brazo del crucero (siguiendo el mismo orden) se le

I 2. Transcripción y versión paleográfica de Víctor Ruiz, apegada al original, tanto en grafía como en disposición de palabras, renglones y párrafos. 
dan de fondo otro medio ancho, es a saber quatro varas, y si fuesen seis, mejor; máxime si llevare colateralles.

Sobre el enrras de los rodapiés se mide el grueso de la pared, que ha de tener o nacer con vara y media, dando la otra media vara que, le sobra al rodapiés, de estribo, por la parte exterior, que por adentro no necesita rodapiés alguno: en este gruesso, y con estas circunstancias va subiendo la pared hasta 8 . varas que se ajustaran con la cornisa, (si la llevare) midiéndolas desde el sobretecho de la cornisa hasta donde nace el grueso de la pared en el enrras del rodapié. Que lleve cornisa, que no, desde esta altura de 8. varas enrrasadas en contorno a nivel, nacen los arcos, y vovedas, pechinas, lunetas etcétera. Según el arte del Maestro que fuere, naciendo los arcos de medio punto desde sus repisas fuertes correspondientes a los pilares; según el arte, y por lo natural le tocan

\section{(IV)}

quatro varas de diámetro $\mathrm{q}^{\circ}$ otro tanto ha de tener el original cintrel desde el centro, para formar el medio punto o círculo: y esso mismo tendrá la cimbra.

La puerta principal de la Iglesia estará bien proporcionada si llevare dos varas y media de ancho, y tres, y 3 quartas de alto. Si fuere de medio punto, se le dará a los pies derechos, desde el alto del sardinel hasta el alto del capitel, dos varas y media y de aquí sale el medio punto, o semicírculo con vara y quarta de dia metro desde el centro, que ha de estar anivelado con los dos capiteles, línea recta. Se supone que los pies derechos han de cargar sobre sus vases, en buena proporción, y según arte, pues el Maestro sabrá muy bien practicar, y perfeccionar el orden que siguiere, que según nuestro estado, y por mas firme, y honesto será el toscano: y este le dará luz, y gobierno para seguir la portada, o fachada y consiguientemente para toda la fábrica. \$ 